\title{
Early risk stratification using Rubidium-82 positron emission tomography in STEMI patients
}

\author{
Adam Ali Ghotbi, MD, ${ }^{\text {a }}$ Philip Hasbak, MD, ${ }^{\text {a }}$ Lars Nepper-Christensen, MD, \\ Jacob Lønborg, MD, PhD, ${ }^{b}$ Kiril Atharovski, MD, PhD, ${ }^{b}$ Thomas Christensen, \\ $M D,{ }^{a}$ Lene Holmvang, MD, DMSc, ${ }^{\mathrm{b}}$ Thomas Engstrøm, MD, DMSc, ${ }^{\mathrm{b}}$ \\ Rasmus Sejersten Ripa, MD, DMSc, ${ }^{a}$ and Andreas Kjær, MD, PhD, DMSc ${ }^{a}$ \\ a Department of Clinical Physiology, Nuclear Medicine \& PET and Cluster for Molecular Imaging, \\ Rigshospitalet University of Copenhagen, Copenhagen, Denmark \\ b Department of Cardiology, The Heart Center, Rigshospitalet University of Copenhagen, \\ Copenhagen, Denmark
}

Received Feb 24, 2017; accepted Jun 30, 2017

doi: 10.1007/s12350-017-0993-x

Background. Assessment of infarct size after myocardial infarction is predictive of subsequent morphological changes and clinical outcome. This study aimed to assess subacute postintervention Rubidium-82 $\left({ }^{82} \mathrm{Rb}\right)$-PET imaging in predicting left ventricle ejection fraction, regional wall motion, and final infarct size by CMR at 3-months after STEMI.

Methods. STEMI patients undergoing percutaneous coronary intervention were included prospectively. Rest-only ${ }^{82} \mathrm{Rb}$-PET perfusion imaging was performed at median 36 hours [IQR: 22 to 50] after the treatment. The extent of hypoperfusion and absolute blood flow $(\mathrm{mL} \cdot \mathrm{min} \cdot \mathrm{g})$ were estimated on a global and a 17-segment model with dedicated software. At 3-months follow-up patients completed the CMR functional and late gadolinium enhancement imaging.

Results. 42 patients were included, but only 35 had follow-up CMR and constituted the study population. Absolute blood flow was significantly lower in the infarct-related territory compared to remote myocardium, $P<.005$. Extent of hypoperfusion correlated with final infarct size, $r=0.58, P<.001$, while blood flow correlated with ejection fraction, $r=0.41$, $P<.05$. In linear mixed models, higher subacute absolute blood flow $(\beta=4.6$, confidence interval $\left.[3.5 ; 5.2], P<.001, R^{2}=0.67\right)$ was associated with greater wall motion. Segmental extent of subacute hypoperfusion $\left(\beta=0.43[0.38 ; 0.49], P<.001, R^{2}=0.58\right)$ was associated with the degree of late gadolinium enhancement at 3 -months.

Conclusions. Subacute rest-only ${ }^{82}$ Rb-PET is feasible following STEMI and seems predictive of myocardial function and infarct size at 3-months. (J Nucl Cardiol 2019;26:471-82.)

Key Words: Positron emission tomography $\cdot$ cardiac magnetic resonance $\cdot$ Rubidium-82 • myocardial blood flow $\cdot$ ST-segment elevation myocardial infarction $\cdot$ final infarct size

Electronic supplementary material The online version of this article (doi:10.1007/s12350-017-0993-x) contains supplementary material, which is available to authorized users.

The authors of this article have provided a PowerPoint file, available for download at SpringerLink, which summarises the contents of the paper and is free for re-use at meetings and presentations. Search for the article DOI on SpringerLink.com
Reprint requests: Adam Ali Ghotbi, MD, Department of Clinical Physiology, Nuclear Medicine \& PET and Cluster for Molecular Imaging, Rigshospitalet University of Copenhagen, Blegdamsvej 9, 2100 Copenhagen, Denmark; adamghotbi@gmail.com

$1071-3581 / \$ 34.00$

Copyright (c) 2017 The Author(s). This article is an open access publication 


\begin{tabular}{|ll|}
\hline Abbreviations \\
AHA-17 & $\begin{array}{l}\text { American heart association 17-segment } \\
\text { model }\end{array}$ \\
& Acute myocardial infarction \\
AMI & Cardiac magnetic resonance \\
CMR & Final infarct size \\
FIS & Infarct-related artery \\
IRA & Late gadolinium enhancement \\
LGE & Left ventricle \\
LV & Left ventricle ejection fraction \\
LVEF & Myocardial perfusion imaging \\
MPI & Primary percutaneous coronary \\
pPCI & intervention \\
& Positron emission tomography \\
PET & Single-photon emission computed \\
SPECT & tomography \\
& ST-segment elevation myocardial \\
STEMI & infarction \\
& Rubidium- 82 \\
${ }^{82} \mathrm{Rb}$ & Technetium-99m \\
${ }^{99 \mathrm{~m}} \mathrm{Tc}$ &
\end{tabular}

\section{INTRODUCTION}

The assessment of left ventricular function and final infarct size (FIS) in the chronic phase after an STelevation myocardial infarction (STEMI) is clinically important because these parameters impact patient management and risk stratification. ${ }^{1-3}$ Infarct size measured by single-photon emission computed tomography (SPECT) at discharge after STEMI has been extensively validated and is predictive of subsequent morphological and functional left ventricular (LV) changes. ${ }^{4-8}$ Albeit readily available at most institutions, its use has not become clinical routine in prognostic evaluation of STEMI patients, perhaps due to low resolution and high time consumption. Another post-pPCI imaging method to risk-stratify STEMI patients is cardiac magnetic resonance (CMR). CMR-derived measurements have been associated with LV morphological changes and clinical outcome after STEMI. ${ }^{3,9,10}$ However, CMR cannot be performed in a considerable number of patients due to contraindications, and it is also a time-consuming technique. Rest positron emission tomography (PET) using Rubidium-82 ( $\left.{ }^{82} \mathrm{Rb}\right)$ tracer has no absolute contraindications and provides rest myocardial perfusion imaging (MPI) in less than 15 minutes in absolute terms (milliliters-minute-gram), which extends the scope of conventional semi-quantitative SPECT. The time aspect combined with the possibility of proper patient monitoring during the examination becomes increasingly important with the decreasing hospitalization time and the widespread use of early transfer (same day) to local hospitals that may not have the same imaging facilities. We have previously reported about the feasibility of ${ }^{82} \mathrm{Rb}-$ PET in assessing the infarct size subacutely after STEMI compared to SPECT and CMR. ${ }^{11}$

This prospective cohort study aims to uncover whether PET derived measurements of resting blood flow and extent of severe hypoperfusion in the subacute phase of STEMI can predict final infarct size, LVEF, and regional wall motion as measured by CMR at 3months follow-up.

\section{METHODS}

Patients with index STEMI were prospectively included in the study (Figure 1). Other results from 12 of these patients have previously been reported in a separate study. ${ }^{11}$ Inclusion criteria were symptom duration less than 12 hours and STEMI in the ECG defined as ST- segment elevation in 2 contiguous electrocardiographic (ECG) leads of $>0.1 \mathrm{mV}$ in $\mathrm{V}_{4}-\mathrm{V}_{6}$ or leads II, III, and aVR, or $>0.2 \mathrm{mV}$ in lead $\mathrm{V}_{1}-\mathrm{V}_{3}$. Exclusion criteria were cardiogenic shock, previous MI, stent thrombosis, unconsciousness, or previous coronary artery bypass grafting. All patients were pretreated with standard therapy, including oxygen, sublingual nitroglycerin, aspirin (300 mg), prasugrel (60 mg), and heparin (10,000 units i.v.) in the prehospital setting. The infarct-related vessel was identified by coronary angiography, and pPCI was performed according to international guidelines. Patients were treated lifelong with $75 \mathrm{mg}$ aspirin and $10 \mathrm{mg}$ prasugrel daily for 12 months.

Standard echocardiography was performed according to guidelines, routinely at discharge. Blood was sampled for creatine-kinase $\mathrm{MB}$ and Troponin $\mathrm{T}$ immediately before PCI and four additional times at fixed time-points post-PCI.

At 3-months follow-up, patients were interviewed to exclude any admission for restenosis/angina, and in addition, patient journals were audited.

\section{Ethics}

The independent local ethics committee approved this study, protocol no: H-4-2010-054. All patients included received verbal and written information, and written consent was obtained from all the patients before inclusion in compliance with the Declaration of Helsinki.

\section{PET Acquisition}

Rest PET MPI was performed the subsequent day after pPCI and when patients were clinically stable. The protocol has been described previously. ${ }^{11}$ In brief, patients were under constant visual and ECG monitoring and placed in supine position in a Siemens Biograph mCT/PET 64-slice scanner (Siemens Medical, Knoxville, TN, USA). For attenuation correction, a low-dose CT scan was acquired, and subsequently, patients were administrated approximately $1100 \mathrm{MBq}$ of ${ }^{82} \mathrm{Rb}$ i.v. (Cardiogen $\cdot 82^{\circledR}$, Bracco Diagnostics Inc., USA) 


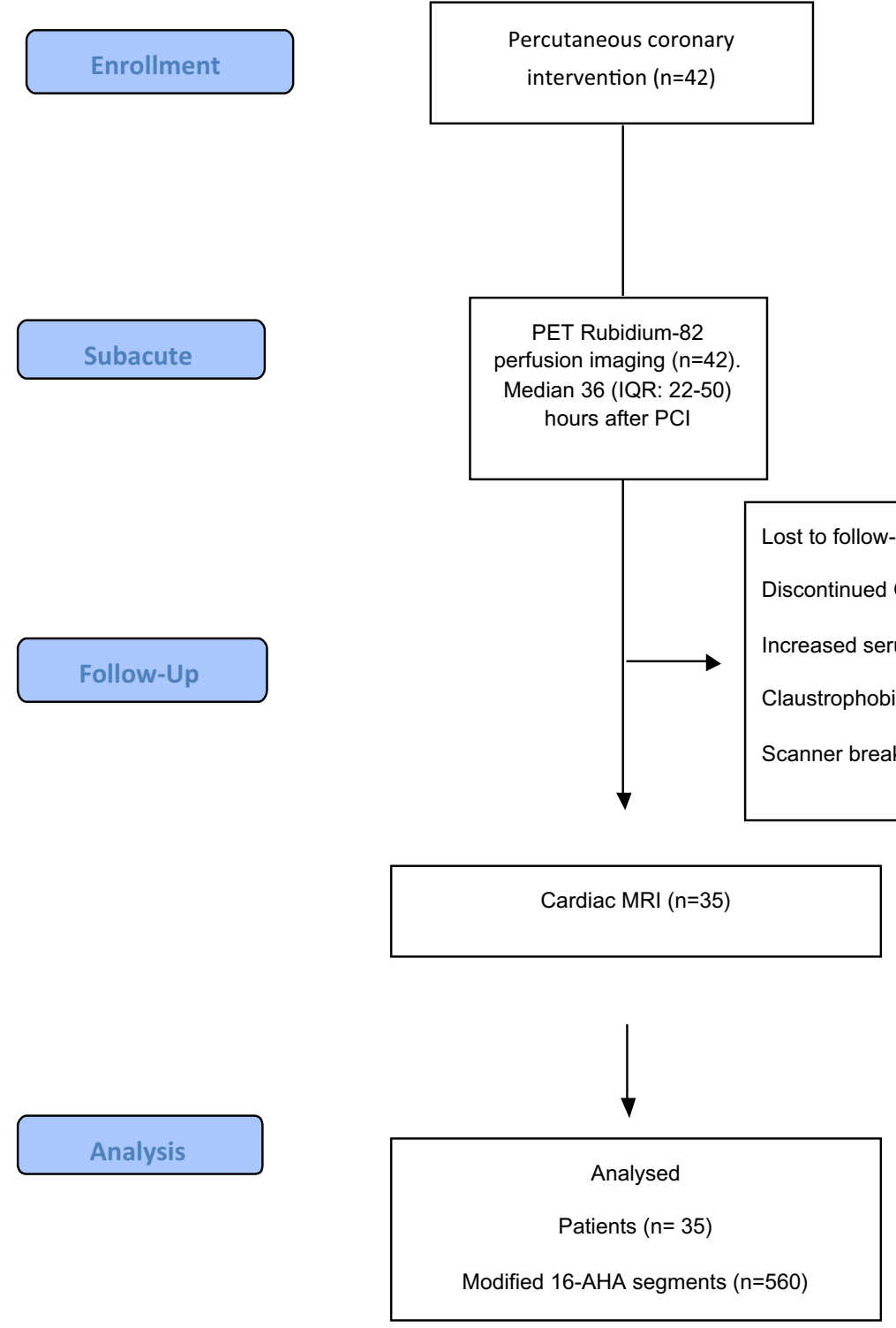

Figure 1. Study design. PET, positron emission tomography; $C M R$, cardiac magnetic resonance imaging; $A H A$, American Heart Association.

and underwent 7 minutes of 3D list mode dynamic data acquisition. PET and CT images were manually inspected for any misalignment and corrected if necessary before reconstruction of attenuation-corrected images. Images were reconstructed into 21 frames $(12 \times 10$ seconds, $3 \times 20 \mathrm{sec}-$ onds, $6 \times 30$ seconds) with attenuation, scatter, and decay corrections using 3D iterative ordered-subsets expectation maximization, Gaussian filtering with $10 \mathrm{~mm}$ full width at half maximum, including time-of-flight and point-spread-function. Examination time was approximately 15 minutes.

Cedars QPS/QGS ${ }^{\circledR}$ software (v. 2012, Cedars Sinai, USA) was used to process and analyze semi-quantitative and quantitative data in a semi-automated manner. Two experienced observers assessed the accuracy of slice-alignments in the ventricular planes and intervened if necessary (blinded to
CMR data). Disagreements were solved by consensus. Tracer uptake was normalized to maximal uptake (index 100).

Myocardial perfusion was quantified using two methods: extent of hypoperfusion and absolute myocardial blood flow. Quantitation of the extent of severe hypoperfusion in the left ventricle was determined by an automated algorithm with a threshold of 2.5 standard deviations (SD) below normal counts in each pixel and estimated as percent of the LV volume and per AHA-17 segment model. ${ }^{12}$ The normal limit approach with cutoff $2.5 \mathrm{SD}$ was prespecified in our protocol and was chosen since it has previously been used to estimate final infarct size in SPECT. ${ }^{13}$ However, the optimal cut-off value for follow-up assessments after STEMI remains unknown when using PET. ${ }^{11}$ Absolute rest myocardial blood flow $(\mathrm{ml} \cdot \mathrm{min} \cdot \mathrm{g})$ was calculated by applying Lortie's one compartment model ${ }^{14}$ and was expressed as global 
myocardial blood flow, regional myocardial blood flow, and myocardial blood flow per AHA-17 segment. Rest myocardial blood flow was indexed to rate-pressure product and multiplied by $10,000 \mathrm{mmHg} \cdot \mathrm{s}$. The AHA-17 segment model was reformatted to a 16-segment model (the apical segment was disregarded) to accommodate the corresponding CMR 16-segment model.

\section{CMR Acquisition}

Follow-up imaging was performed 3 months after pPCI on a $1.5 \mathrm{~T}$ scanner (Avanto, Siemens, Erlangen, Germany) with the use of a 6-channel body array coil. Functional assessment of the LV was performed using an ECG-triggered balanced steadystate free-precession cine sequence covering the entire LV (slice thickness $8 \mathrm{~mm}$, slice gap $0 \mathrm{~mm}$, echo time $1.5 \mathrm{~ms}$, field of view $300 \mathrm{~mm}$, and 25 frames per heart beat). Final infarct size (FIS) was quantified 10 minutes after administration of Gadoliniumbased contrast $(0.1 \mathrm{~mL} \cdot \mathrm{kg}$; Gadovist, Bayer Schering, Berlin, Germany). An ECG-triggered enhancement inversion-recovery was used (slice thickness, $8 \mathrm{~mm}$; field of view, 300 to $360 \mathrm{~mm}$; echo time, $1.4 \mathrm{~ms}$, slice gap $0 \mathrm{~mm}$ ). In short-axis images of the $\mathrm{LV}$, the inversion time was adjusted in each slice from base to apex in order to null the signal from the normal myocardium.

On short-axis cine images endo- and epicardial contours were manually drawn on End-diastolic and End-systolic frames. Papillary muscles were incorporated into the LV lumen volume. LV volumes, wall thickening in percent, and wall motion in millimeters were subsequently obtained automatically from the software.

Wall thickening was calculated by expressing the endsystolic increase for each AHA-16 segment as a percentage of its end-diastolic wall thickness ((end-systolic - end-diastolic) $\times$ 100/ end-diastolic). Each AHA-16 segment was categorized as normal, hypokinetic or hyperkinetic based on a normal database of wall thickening. ${ }^{15}$ Modified AHA-16 segments polar maps were generated after manually determining the right ventricle's superior and inferior insertion on the LV.

FIS was assessed on the late gadolinium enhancement images after manual endo- and epicardial contour tracking. FIS was defined as hyper-intensive myocardium ( $>5 \mathrm{SD}$ of the mean intensity of normal reference myocardium). FIS was calculated as percent of the LV volume and percent transmurality per AHA-16 segment. The analyses were performed by two experienced observers that were blinded to PET data using $\mathrm{CVI}^{42}$ (Circle Cardiovascular Imaging Inc., Calgary, Canada)

\section{Statistical Analyses}

Continuous normally distributed variables are summarized as mean $\pm \mathrm{SD}$ and non-normally distributed continuous variables as median (interquartile range, [IQR]) and categorical variables as frequencies or percent $(\%)$. Generalized Estimating Equations' test was used when comparing three variables. The MannWhitey test was used for comparisons between two independent groups. Correlation between any two modalities was examined with Spearman's rank correlation. Correlations less than 0.39 were interpreted as "fair," values between 0.40 and 0.59 as "moderate," and values above as "strong", ${ }^{16}$
In order to assess the predictive ability of subacute ${ }^{82} \mathrm{Rb}$ PET for follow-up cardiac function and morphology three different sets of predictors corresponding to models of increasing complexity were considered. Model 1 contains only PET derivatives as explanatory variables; model 2, in addition, included AHA-17 segments, infarct-related artery segments, and vascular territory. These variables were included to adjust for differences in regional tracer uptake due to physiological and pathophysiological circumstances ${ }^{17,18}$; model 3 further included age, gender, tobacco, diabetes, hypercholesterolemia, hypertension, time from symptom-onset to pPCI, apoplexia, familiar disposition, and Thrombolysis In Myocardial Infarction-flow, which are commonly acknowledged as risk factors in follow-up morbidity and mortality and infarct size after STEMI. ${ }^{19}$ Linear mixed models were used for the analyses in order to account for correlation between segments belonging to the same subjects. For comparison, mixed model analyses were also performed using routine discharge echocardiography ejection fraction; and peak Troponin T and peak creatine-kinase MB as predictors. For all predictive models, the $R^{2}$ (variance explained) was estimated according to Nakagawa et $\mathrm{al}^{20}$ All statistical analyses were performed using SPSS ${ }^{\circledR}$ version 19 (IBM SPSS, Chicago, IL, USA).

\section{RESULTS}

A total of 42 Patients were recruited for the study, but seven were lost to follow-up CMR (Figure 1). The 35 patients with both subacute ${ }^{82} \mathrm{Rb}$-PET MPI and follow-up CMR constituted the study population. Baseline demographics and medical history for patients enrolled are summarized in Table 1. The culprit artery was left anterior descending artery in 53\% of the patients, and 69\% had a Thrombolysis In Myocardial Infarction-flow of 0 to 1 prior to pPCI.

\section{PET Measurements}

Rest PET MPI was performed at a median of 36 hours $[22 ; 50]$ after pPCI. The median myocardial area with severe hypoperfusion was $20.0 \%$ of the LV [IQR: 7.5; 35.0] in the subacute phase. Absolute median global blood flow, blood flow in the infarct-related artery territory (IRA), and blood flow in the non-IRA territory were 0.94 $[0.78 ; 1.12], 0.71[0.57 ; 0.95]$ and $1.0[0.86 ; 1.16]$ $\mathrm{mL} \cdot \mathrm{min} \cdot \mathrm{g}$, respectively. Blood flow at IRA territory was significantly lower than the global blood flow and the blood flow at non-IRA territory $(P<.005$ for difference).

\section{CMR Measurements}

At follow-up (median 93 days, [91; 96] 35 patients were examined. Median LVEF was 55\% [49; 60]. Median LV End-diastolic and End-systolic volumes were $172 \mathrm{~mL}[143 ; 210]$ and $79 \mathrm{~mL}$ [57; 98], respectively. Median FIS was $13.9 \%[9.5 ; 22.0]$ of the LV 
volume. A total of 273 out of 560 segments (48\%) had late gadolinium enhancement (LGE; transmurality range 1 to $97 \%$, median $17 \%$ [3; 41]). LGE, wall thickening, and wall motion stratified by wall function categories are listed in Table 2 .

\section{Relationship Between Subacute PET and Follow-Up CMR Measurements: Global Level}

As presented in Table 3, PET derived variables correlated from "fair" to "moderate" with CMR derivatives. On a patient-to-patient basis, the best and strongest correlation was found between extent of severe hypoperfusion with CMR FIS. The extent of severe hypoperfusion had a moderate correlation with CMR LVEF and LV end-systolic volume at follow-up. Global absolute flow by PET had a moderate correlation with CMR LVEF and LV end-systolic volume at follow-up.

\section{Predictive Power of PET Measurements On a Segmental Level}

The extent of hypoperfusion and myocardial blood flow stratified by wall function categories is summarized in Table 2.

In order to assess the predictive ability of subacute ${ }^{82} \mathrm{Rb}$-PET for follow-up cardiac function and morphology three different prediction models of increasing complexity were considered. Results are listed in Table 4 for each model with different adjusted variables. We found that model 2, which further includes AHA-17 segments, infarct-related artery segments, and vascular territory as predictors, best predicted the outcomes in terms of a substantially higher variances explained (i.e., $R^{2}$ ) compared to the simple model which only includes the PET derivatives as predictors (model 1). ${ }^{20}$ Model 3 performed marginally better than model 2 in terms of $R^{2}$, but at the expense of higher complexity. The estimates of model 2 are reported below.

PET derived variables on a segment-to-segment basis were all significant predictors of CMR parameters. Absolute blood flow showed the best model fit for predicting wall motion at follow-up, $(\beta=4.6$, confidence interval $[3.5 ; 5.2], P<.001, R^{2}=0.67$ ); such that for every $0.1 \mathrm{~mL} \cdot \mathrm{min} \cdot \mathrm{g}$ increase of blood flow, there was a $0.46 \mathrm{~mm}$ increase in the wall motion during systole. The extent of severe hypoperfusion was best in predicting LGE transmurality, $(\beta=0.43[0.38 ; 0.49]$, $P<.001, R^{2}=0.58$ ); such that for every $1 \%$ increase of extent of severe hypoperfusion, there was $0.43 \%$ increase in LGE transmurality per segment.
Table 1. Baseline characteristics

\section{Patients \\ $(n=35)$}

\begin{tabular}{|c|c|}
\hline Age & $58 \pm 9$ years \\
\hline Male & $29(83 \%)$ \\
\hline Hypertension & $11(26 \%)$ \\
\hline Hypercholesterolemia & $7(17 \%)$ \\
\hline Total cholesterol, mmol/L & $4.9 \pm 0.8 \mathrm{mmol} / \mathrm{L}$ \\
\hline Diabetes & $1(2 \%)$ \\
\hline \multicolumn{2}{|l|}{ Smoking } \\
\hline Non & $10(24 \%)$ \\
\hline Active & $18(43 \%)$ \\
\hline Ex & $14(33 \%)$ \\
\hline Family history of premature CAD & $17(41 \%)$ \\
\hline Peripheral arterial disease & 0 \\
\hline \multicolumn{2}{|l|}{ Infarct location } \\
\hline LAD & 17 (49\%) \\
\hline RCA & $15(42 \%)$ \\
\hline LCX & $2(6 \%)$ \\
\hline LM & $1(3 \%)$ \\
\hline \multicolumn{2}{|l|}{ TIMI flow prior to $\mathrm{pPCI}$} \\
\hline 0 & 17 (49\%) \\
\hline 1 & $8(23 \%)$ \\
\hline 2 & $5(14 \%)$ \\
\hline 3 & $5(14 \%)$ \\
\hline \multicolumn{2}{|l|}{ TIMI flow post-pPCI } \\
\hline 0 & $1(2 \%)$ \\
\hline 1 & 0 \\
\hline 2 & $3(9 \%)$ \\
\hline 3 & $31(89 \%)$ \\
\hline Peak troponin $\mathrm{T}, \mathrm{ng} / \mathrm{mL}$ & $5769 \pm 6201$ \\
\hline Peak CK-MB, U/I & $247 \pm 175$ \\
\hline $\begin{array}{l}\text { Ejection fraction post-pPCI at } \\
\text { discharge, } \%\end{array}$ & $43.8 \pm 9.6$ \\
\hline $\begin{array}{l}\text { Time from symptom-onset to } \mathrm{PCI} \text {, } \\
\text { minutes (IQR) }\end{array}$ & $165(120-273)$ \\
\hline \multicolumn{2}{|l|}{ Medication during follow-up } \\
\hline ACE/ARB & $11(31 \%)$ \\
\hline Beta-blockers & $31(88 \%)$ \\
\hline Statins & $35(100 \%)$ \\
\hline Thiazide/loop diuretic & $6(17 \%)$ \\
\hline Acetylsalicylic acid & $35(100 \%)$ \\
\hline ADP antagonist & $35(100 \%)$ \\
\hline
\end{tabular}

$C A D$, coronary artery disease; $L A D$, left anterior ascending artery; $R C A$, right coronary artery; $L C X$, left circumflex artery; $L M$, left main artery; TIMI, thrombolysis in myocardial infarction; $P P C l$, post-primary percutaneous intervention; $C K$ $M B$, Creatine-kinase $M B ; I Q R$, interquartile range; $A C E / A R B$, angiotensin-converting-enzyme inhibitor/angiotensin receptor II blocker; $A D P$ antagonist, adenosine diphosphate (ADP) receptor inhibitor 
Table 2. Follow-up CMR measurements of wall thickening and subacute blood flow by ${ }^{82} \mathrm{Rb}-\mathrm{PET}$ on segmental level

\begin{tabular}{|c|c|c|c|c|}
\hline & Hypokinetic & Normal & Hyperkinetic & $\begin{array}{c}P \\
\text { value }\end{array}$ \\
\hline Segments $(n)$ & 238 & 263 & 59 & \\
\hline Wall thickening (\%) & $31(11-45)^{*}$ & $70(57-86)$ & $118(108-128)$ & $<.001$ \\
\hline Wall motion (mm) & $4.7(2.4-7.1)^{*}$, & $8.1(5.9-10.6)$ & $10.3(7.9-12.3)$ & $<.001$ \\
\hline LGE follow-up, \% of segment & $13.8(0-45.7)^{*}$, & $0(0-10.0)$ & $0(0-1.9)$ & $<.001$ \\
\hline $\begin{array}{l}{ }^{82} \mathrm{Rb}-\text { extent of severe hypoperfusion (\% of } \\
\text { segment) }\end{array}$ & $13(0-72)^{*}$ & $0(0-23)$ & $0(0-11)$ & $<.001$ \\
\hline${ }^{82} \mathrm{Rb}-$ absolute blood flow $(\mathrm{ml} \cdot \mathrm{min} \cdot \mathrm{g})$ & $0.81(0.63-1.02)^{*}$, & $0.97(0.78-1.20)$ & $1.22(0.93-1.34)^{*}$ & $<.001$ \\
\hline
\end{tabular}

Measurements from follow-up wall thickening and wall motion with CMR and subacute setting PET-Rb. Values are median (IQR). AHA-16 model segments of abnormal, normal, hyperkinetic wall thickening as measured by CMR and stratified according to normal database

LGE follow-up, late gadolinium enhancement at follow-up per segment; $R b$, Rubidium-82 median (IQR) percent of extent severe hypoperfusion per segment, absolute blood flow in $\mathrm{ml} \cdot \mathrm{min} \cdot \mathrm{g}$

${ }^{*} P<.001$ for difference vs. normal wall thickening segments

${ }^{\top} P<.02$ for difference vs. hyperkinetic wall thickening segments

Table 3. Correlation between subacute PET and follow-up CMR

\begin{tabular}{lcccc}
\hline & \multicolumn{4}{c}{ Correlation coefficient (r) } \\
\cline { 2 - 4 } \multicolumn{1}{c}{ Variables } & \multicolumn{3}{c}{ CMR follow-up (N = 35) } \\
\cline { 2 - 4 } & LVEF (\%) & LVEDV (mL) & LVESV (mL) & FIS (\% of LV) \\
\hline Extent of severe hypoperfusion (\%) & $-0.53^{* *}$ & 0.31 & $0.48^{* *}$ & $0.58^{* * *}$ \\
Global blood flow (ml-min.g) & $0.41^{*}$ & -0.22 & $-0.42^{*}$ & -0.32 \\
\hline
\end{tabular}

Correlations between PET derivatives and CMR follow-up outcomes on a patient basis

$C M R$, cardiac magnetic resonance imaging; $L V E F$ left ventricle ejection fraction; $L V E D V$ left ventricle end-diastolic volume; $L V E S V$ left ventricle end-systolic volume; FIS final infarct size; $P E T$, positron emission tomography

${ }^{*} P<.05$

$* * P<.01$

$* * * P<.001$

Routine procedures such as echocardiography ejection fraction at discharge and blood samples of Troponin $\mathrm{T}$ and creatine-kinase MB are cheap and readily available tests. Therefore, a head-to-head comparison of new diagnostic tests is warranted. Variances explained by these tests were all substantially less than those explained by PET derivatives regarding CMR outcomes. See Table 5.

\section{PET Measures of Extent of Severe Hypoperfusion and Blood Flow: Relation to CMR LVEF}

We stratified the cohort $(n=35)$ according to follow-up LVEF tertiles and compared patients in the lower third tertile (Group 1; $n=12$ ) with the upper two tertiles (Group 2; $n=23$ ). This was done in order to put the PET measurements at the subacute phase in the context of an important and valuable clinical parameter, LVEF. Median LVEF was 48.0\% (43.0; 50.5) in Group 1 compared to $60 \%(55.0 ; 63.6)$ in Group $2(P=.001)$. Baseline characteristics for the two groups are shown in Table 6. Median extent of severe hypoperfusion at the subacute phase was significantly higher in Group 1 $(37 \%,[13 ; 46]$ compared to Group $2(20 \%,[7 ; 27]$ $(P=.02)$. Furthermore, global blood flow and blood flow in the IRA were significantly lower in Group 1 compared to Group 2, see Figure 2.

\section{DISCUSSION}

The present study examined the ability of resting ${ }^{82} \mathrm{Rb}$-PET imaging performed in patients' days after STEMI treated with pPCI to predict subsequent morphological features as detected with CMR at follow-up. We found in a small sample of STEMI population that 


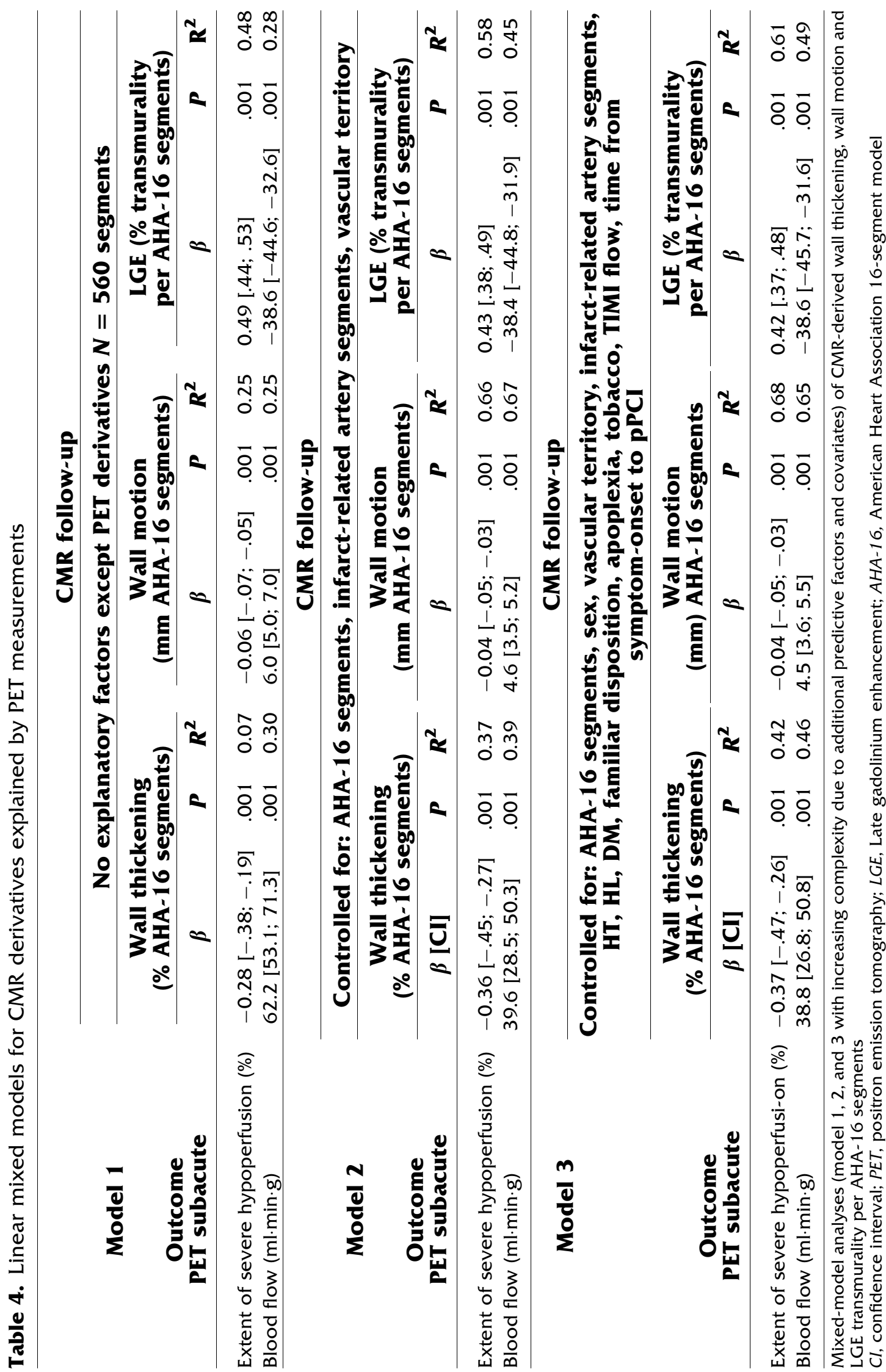


PET MPI seems to forecast the degree of wall motion impairment and amount of scar. Furthermore, subacute blood flow measurement by PET was significantly lower in patients with reduced LVEF at 3-months follow-up compared to those with preserved LVEF. Together, these results are encouraging for further and larger trials investigating the clinical utility of ${ }^{82} \mathrm{Rb}$-PET in the subacute management of the STEMI patient for optimal and individualized risk stratification and tertiary prevention.

Gallagher et al established that an akinetic myocardial segment can either be infarcted, hibernating or stunned, and for the two latter conditions still salvageable. ${ }^{21}$ Hence, review of cardiac function after STEMI alone can conceal later functional recovery. Our study confirms that injury of the microcirculation as evaluated with ${ }^{82} \mathrm{Rb}$-PET after pPCI is associated with cardiac function at follow-up. This is important since the efficiency of pPCI and adjuvant therapy can be evaluated with ${ }^{82} \mathrm{Rb}$-PET in a fast, standardized and observerindependent way quickly after the STEMI.

Recently, perfusable tissue index (a marker for viability) derived from $\left[{ }^{15} \mathrm{O}\right]-\mathrm{H}_{2} \mathrm{O}$ PET imaging, was shown to predict the recovery of segments assessed by $\mathrm{CMR}^{22}$ This finding is in line with our results, where extent of severe hypoperfusion was predictive of the LGE transmurality at follow-up. ${ }^{82} \mathrm{Rb}$-PET imaging may be considered more advantageous with no need of an onsite cyclotron, which is necessary for producing $\left[{ }^{15} \mathrm{O}\right]-$ $\mathrm{H}_{2} \mathrm{O}$. The monthly costs associated with an ${ }^{82} \mathrm{Rb}$ generator must be taken into consideration. But, since many centers use ${ }^{82} \mathrm{Rb}$ MPI to assess the severity of coronary artery disease, ${ }^{23}$ it would be economically feasible to expand its role to the early post-STEMI phase once the procurement is established.

CMR-assessed FIS has previously been shown to be a strong predictor of subsequent cardiac events ${ }^{3,10}$ and the extent of LGE (segmental scar burden) has been shown to correspond to the histologically verified scar area. ${ }^{24}$ Therefore, the association between the extent of severe hypoperfusion with PET imaging and FIS and LGE transmurality derived from CMR at follow-up is an important aspect of this study. It emphasizes the potential of diagnostic and therapeutic targets in the microcirculation in patients following AMI.

Previously, research groups have demonstrated the benefits of myocardial perfusion imaging in post-infarction patients regarding functional recovery, LVEF, and cardiovascular death. ${ }^{1,4,7,8,25,26}$ Common for them are the use of conventional SPECT imaging which has lower spatial and temporal resolution than PET and is more cumbersome to perform, ${ }^{23}$ as well as mixed treatment strategies for STEMI (e.g., intravenous thrombolysis or PCI) and inconsistent treatment after STEMI. 


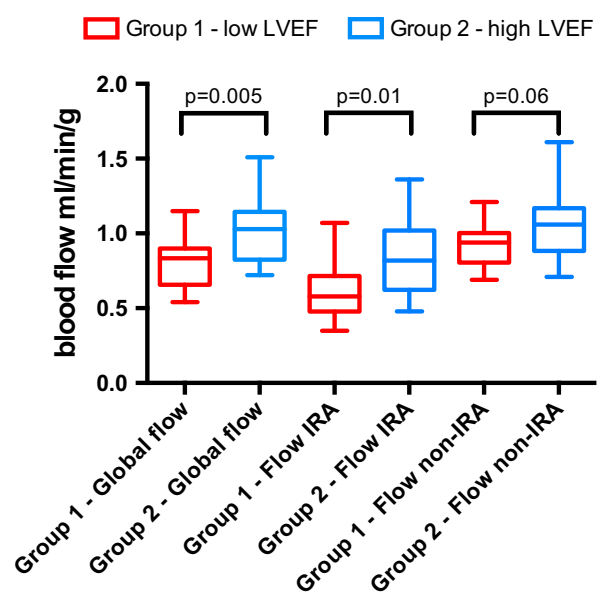

Figure 2. Blood flow measurements in low and high LVEF groups. $L V E F$, left ventricle ejection fraction; IRA, infarctrelated artery.

A Mayo Clinic study demonstrated that discharge infarct size measured with ${ }^{99 \mathrm{~m}} \mathrm{Tc}$ - sestamibi on SPECT was not significantly correlated to discharge LVEF (determined by electron beam CT), but became so after remodeling had progressed at 6-weeks $(r=-0.83$, $P=0.0003)$ and 1-year $(r=-0.84, P=0.0002){ }^{4}$ The ${ }^{99 \mathrm{~m}}$ Tc- sestamibi SPECT imaging was performed on average $7 \pm 2$ days after admission, whereas, our PET imaging was performed earlier at a median of 36 hours after primary PCI. This could be one explanation for the difference in correlation coefficient between ours and the Mayo Clinic study. Ndrepepa et al reported similar moderate correlation as ours between initial perfusion defect size and LVEF at follow-up examined in 626 patients with MI $(r=-0.52, P<.001){ }^{26}$ The authors explained the relative moderate correlation as a result of a mismatch between ${ }^{99 m}$ Tc-sestamibi uptake and LVEF due to stunning. The extent of ${ }^{82} \mathrm{Rb}$ uptake affected by stunning remains unclear. ${ }^{82} \mathrm{Rb}$ is dependent on both the blood flow rate and the metabolic state of the myocardium. ${ }^{27}$ One preclinical study showed significantly lower absolute blood flow in areas of stunned myocardium compared to remote areas measured with ${ }^{82} \mathrm{Rb}$.

A study comparable to ours, confirm that areas with reduced wall motion were associated with decreased stress blood flow as well as reserve blood flow capacity as assessed 24 months after index MI with ${ }^{13} \mathrm{~N}$-ammonia PET imaging. ${ }^{28}$ Similarly, Juárez-Orzco et al found that myocardial flow reserve in the spared myocardium in patients with previous MI was a better predictor of LVEF than infarct size. ${ }^{29}$ Our results suggest that areas with hypokinetic, normal, and hyperkinetic wall functioning at follow-up have dissimilar rest ${ }^{82} \mathrm{Rb}$-uptake already at the subacute state. Whether this is due to decreased extraction of the tracer during reactive hyperemia and/or the metabolic state of the myocardium as a ramification of the ischemia/reperfusion injury remains uncertain. We find that rest-only PET perfusion imaging in the subacute phase after MI seems sufficient to predict future cardiac contractility. However, it is well-known that the myocardial flow reserve adds more information regarding the microcirculatory status than rest-only imaging. We can only speculate if this would also be the case in our population. However, since stress testing is contraindicated in the subacute phase of an MI, this could not be tested in our study.

Our results could indicate that a single non-stress examination lasting less than 15 minutes performed during initial admission after an STEMI could add prognostic information to the cardiologist that could potentially individualize risk-management of follow-up surveillance. However, the ${ }^{82} \mathrm{Rb}$-PET examination has not been optimized for this indication. One example is our assessment of extent of hypoperfusion using a cutoff value of $2.5 \mathrm{SD}$, this value is derived from SPECT examinations of perfusion, and we have recently shown that this value is probably not optimal. ${ }^{11}$ SPECT and MRI are alternative methods that could be performed to gain similar information. These methods are more validated for this indication, but patient characteristics and/or local conditions may encounter when choosing the best method for the individual patient.

Another PET imaging method to predict regional and global LV function recovery is fluorodeoxyglucose (FDG). FDG-PET showed good sensitivity and specificity in predicting improvement in regional function after revascularization in patients with chronic coronary artery disease. ${ }^{30}$ FDG-imaging is a well-validated method for viability testing, ${ }^{30}$ but the interpretation of increased glucose uptake in the early stages after infarction is less clear ${ }^{31}$ and could be influenced by the active myocardial inflammation.

Although the LVEF of group 1 (48\%) was not substantially reduced and would be considered near normal, the ${ }^{82} \mathrm{Rb}$-PET imaging was able to differentiate between patients with high and low LVEF. Cuculi et al found no difference between resting and hyperemia flow with an invasive measuring technique at pPCI. This was probably due to microcirculatory jeopardization and therefore the inability to obtain hyperemia. But importantly, they found a significantly lower coronary flow reserve the following day in patients with lower LVEF compared to patients with preserved LVEF. ${ }^{32}$ Hence, the microcirculatory function changes during the first 24 hours after STEMI and is still affected although under recovery, stressing that the timing of MPI at approximately 24 hours after STEMI is feasible. 
Table 6. Baseline characteristics of the study population grouped by lower and upper 2 tertiles of ejection fraction

\begin{tabular}{|c|c|c|c|}
\hline & $\begin{array}{c}\text { Group } 1 \text {-low LVEF } \\
(n=12)\end{array}$ & $\begin{array}{c}\text { Group 2-high LVEF } \\
(n=23)\end{array}$ & $\underset{\text { value }}{P}$ \\
\hline Age, years (IQR) & $51(47 ; 65)$ & $60(55 ; 69)$ & .24 \\
\hline Systolic BP (mmHg) & $129(116 ; 145)$ & $123(114 ; 143)$ & .9 \\
\hline Diastolic BP (mmHg) & $83(68 ; 94)$ & $72(64 ; 82)$ & .09 \\
\hline Heart rate $(/ \mathrm{min})$ & $68(63 ; 72)$ & $61(53 ; 65)$ & .006 \\
\hline \multicolumn{4}{|l|}{ Coronary risk factors, $n(\%)$} \\
\hline Hypertension & $4 / 12(33)$ & $7 / 23(30)$ & .86 \\
\hline Smoking & $2 / 12(17)$ & $12 / 23(52)$ & .06 \\
\hline Diabetes mellitus & $1 / 12(8)$ & $0 / 23(0)$ & .16 \\
\hline Hyperlipidemia & $2 / 12(17)$ & $3 / 23(13)$ & .77 \\
\hline Apoplexia & $0 / 12(0)$ & $1 / 23(4)$ & .46 \\
\hline Peripheral arterial disease & $0 / 12(0)$ & $0 / 23(0)$ & \\
\hline Familiar disposition & $9 / 12(75)$ & $7 / 23(30)$ & .009 \\
\hline \multicolumn{4}{|l|}{$\mathrm{PCl}$} \\
\hline $\begin{array}{l}\text { Time from symptom-onset to } \mathrm{PCI} \text {, } \\
\text { minutes }\end{array}$ & $210(120 ; 330)$ & $175(122 ; 267)$ & .99 \\
\hline \multicolumn{4}{|l|}{ Infarct location } \\
\hline LAD & $8(53 \%)$ & $11(53 \%)$ & \\
\hline RCA & $3(41 \%)$ & $10(41 \%)$ & .18 \\
\hline LCX & $0(0 \%)$ & $2(0 \%)$ & \\
\hline LM & $1(2 \%)$ & $0(0 \%)$ & \\
\hline TIMI flow before PCI & & & .89 \\
\hline 0 & $6 / 12(50)$ & $12 / 23(53)$ & \\
\hline I & $2 / 12(17)$ & $5 / 23(21)$ & \\
\hline II & $2 / 12(17)$ & $3 / 23(13)$ & \\
\hline III & $2 / 12(17)$ & $3 / 23(13)$ & \\
\hline TIMI flow after PCI & & & .39 \\
\hline 0 & $0 / 12(0)$ & $1 / 23(4)$ & \\
\hline I & $0 / 12(0)$ & $0 / 23(0)$ & \\
\hline II & $2 / 12(17)$ & $1 / 23(4)$ & \\
\hline III & $10 / 12(83)$ & $21 / 23(91)$ & \\
\hline Troponin T peak (ng/L) & $5850(5570 ; 15200)$ & $3570(1855 ; 5920)$ & .002 \\
\hline Creatine-kinase MB peak (ng/L) & $320(250 ; 393)$ & $157(91 ; 289)$ & .04 \\
\hline
\end{tabular}

Values are given in median $(I Q R)$, interquartile range; $B P$, blood pressure; $P C I$ percutaneous coronary intervention; $L A D$, left anterior descending artery; $R C A$, right coronary artery; $L C X$, left circumflex artery; $L M$, left main artery; TIMI, thrombolysis in myocardial infarction

\section{Limitations}

Of potential limitation is the lack of follow-up angiography to insure patent IRA. A silent reocclusion of the IRA after the reperfusion would lead to a deteriorating wall motion function. However, no patients were admitted to the hospital for AMI in the follow-up period, and no patients reported crescendo angina at the 3 -months follow-up. Furthermore, the sample size is relatively small, and all participants were presented to a single center. Hence, confounders such as demographics and treatment can influence the results.
Potential mismatch between CMR and PET could be due to misalignment of segments. However, the standard use of AHA-16 segments should minimize this limitation. Finally, the optimal timing of ${ }^{82} \mathrm{Rb}-\mathrm{PET}$ is uncertain, and since it measures flow at a single time point, the condition of the microcirculation is uncertain as well.

\section{CONCLUSION}

${ }^{82} \mathrm{Rb}$-PET imaging is feasible and can provide fast assessment of the absolute blood flow at the infarct 
territory and the extent of hypoperfusion following STEMI. These parameters seem predictive of myocardial function and infarct size at follow-up, factors that are of clinical importance for prognosis and morbidity.

The management of patients after infarction could thus potentially be enhanced with the knowledge provided by cardiac ${ }^{82} \mathrm{Rb}$-PET imaging and warrants further research in larger study populations.

\section{NEW KNOWLEDGE GAINED}

Our findings could expand the role of ${ }^{82} \mathrm{Rb}$-PET MPI in the early phase after STEMI and enable assessment of absolute blood flow to predict follow-up LV morphology and function in a time-efficient manner.

\section{Acknowledgments}

We thank biostatistician Julie Forman for her much appreciated advice and suggestions on the statistical analyses. This study received support from the Research Grant Committee of Rigshospitalet Copenhagen University Hospital, Copenhagen, Denmark, No: E-22160-07 (Dr. Adam Ali Ghotbi).

\section{Disclosures}

The authors declare that they have no conflict of interest.

\section{Open Access}

This article is distributed under the terms of the Creative Commons Attribution 4.0 International License (http://creativecommons.org/licenses/by/4.0/), which permits unrestricted use, distribution, and reproduction in any medium, provided you give appropriate credit to the original author(s) and the source, provide a link to the Creative Commons license, and indicate if changes were made.

\section{Reference}

1. Gibbons RJ. Tc-99m SPECT sestamibi for the measurement of infarct size. J Cardiovasc Pharmacol Ther 2011;16:321-31.

2. Korup E, Kober L, Torp-Pedersen C, Toft E. Prognostic usefulness of repeated echocardiographic evaluation after acute myocardial infarction. TRACE Study Group. TRAndolapril Cardiac Evaluation. Am J Cardiol 1999;83:a7.

3. Lonborg J, Vejlstrup N, Kelbaek H, Holmvang L, Jorgensen E, Helqvist $S$, et al. Final infarct size measured by cardiovascular magnetic resonance in patients with ST-elevation myocardial infarction predicts long-term clinical outcome: an observational study. Eur Heart J Cardiovasc Imaging 2013;14:387-95.

4. Chareonthaitawee P, Christian TF, Hirose K, Gibbons RJ, Rumberger JA. Relation of initial infarct size to extent of left ventricular remodeling in the year after acute myocardial infarction. J Am Coll Cardiol 1995;25:567-73.

5. Christian TF, Gitter MJ, Miller TD, Gibbons RJ. Prospective identification of myocardial stunning using technetium- $99 \mathrm{~m}$ sestamibi-based measurements of infarct size. J Am Coll Cardiol 1997;30:1633-40.

6. Guenancia C, Cochet A, Humbert O, Dygai-Cochet I, Lorgis L, Zeller M, et al. Predictors of post-stress LVEF drop 6 months after reperfused myocardial infarction: a gated myocardial perfusion SPECT study. Ann Nucl Med 2013;27:112-22.

7. Sciagra R, Imperiale A, Antoniucci D, Migliorini A, Parodi G, Comis G, et al. Relationship of infarct size and severity versus left ventricular ejection fraction and volumes obtained from $99 \mathrm{mTc}-$ sestamibi gated single-photon emission computed tomography in patients treated with primary percutaneous coronary intervention. Eur J Nucl Med Mol Imaging 2004;31:969-74.

8. Miller TD, Christian TF, Hopfenspirger MR, Hodge DO, Gersh BJ, Gibbons RJ. Infarct size after acute myocardial infarction measured by quantitative tomographic $99 \mathrm{mTc}$ sestamibi imaging predicts subsequent mortality. Circulation 1995;92:334-41.

9. Orn S, Manhenke C, Anand IS, Squire I, Nagel E, Edvardsen T, et al. Effect of left ventricular scar size, location, and transmurality on left ventricular remodeling with healed myocardial infarction. Am J Cardiol 2007;99:1109-14.

10. El Aidi H, Adams A, Moons KG, Den Ruijter HM, Mali WP, Doevendans PA, et al. Cardiac magnetic resonance imaging findings and the risk of cardiovascular events in patients with recent myocardial infarction or suspected or known coronary artery disease: A systematic review of prognostic studies. J Am Coll Cardiol 2014;63:1031-45.

11. Ghotbi AA, Kjaer A, Nepper-Christensen L, Ahtarovski KA, Lonborg JT, Vejlstrup N, et al. Subacute cardiac rubidium- 82 positron emission tomography (82Rb-PET) to assess myocardial area at risk, final infarct size, and myocardial salvage after STEMI. J Nucl Cardiol 2016. doi:10.1007/s12350-016-0694-x.

12. Cerqueira MD. Standardized myocardial segmentation and nomenclature for tomographic imaging of the heart: A statement for healthcare professionals from the Cardiac Imaging Committee of the Council on Clinical Cardiology of the American Heart Association. Circulation 2002;105:539-42.

13. Fakhri Y, Busk M, Schoos MM, Terkelsen CJ, Kristensen SD, Wagner GS, et al. Evaluation of acute ischemia in pre-procedure ECG predicts myocardial salvage after primary PCI in STEMI patients with symptoms $>12$ hours. J Electrocardiol 2016;49:278-83.

14. Lortie M, Beanlands RSB, Yoshinaga K, Klein R, Dasilva JN. DeKemp Ra. Quantification of myocardial blood flow with 82Rb dynamic PET imaging. Euro $\mathrm{J}$ Nucl Med Mol Imaging 2007:34:1765-74.

15. Dawson DK, Maceira AM, Raj VJ, Graham C, Pennell DJ, Kilner PJ. Regional thicknesses and thickening of compacted and trabeculated myocardial layers of the normal left ventricle studied by cardiovascular magnetic resonance. Circulation Cardiovasc Imaging 2011;4:139-46.

16. Altman DG. Practical statistics for medical research. London: Chapman and Hall; 1991. p. 404.

17. Hoffman JI. Heterogeneity of myocardial blood flow. Basic Res Cardiol 1995;90:103-11.

18. Javadi MS, Lautamaki R, Merrill J, Voicu C, Epley W, McBride $\mathrm{G}$, et al. Definition of vascular territories on myocardial perfusion images by integration with true coronary anatomy: A hybrid PET/ CT analysis. J Nucl Med 2010;51:198-203.

19. Stone GW, Selker HP, Thiele H, Patel MR, Udelson JE, Ohman EM, et al. Relationship between infarct size and outcomes following primary PCI: Patient-level analysis from 10 randomized trials. J Am Coll Cardiol 2016;67:1674-83.

20. Nakagawa S, Schielzeth H. A general and simple method for obtaining $R^{\wedge} 2$ from generalized linear mixed-effects models. Methods Ecol Evol 2013;2013:133-42. 
21. Gallagher KP, Kumada T, Koziol JA, McKown MD, Kemper WS, Ross J Jr. Significance of regional wall thickening abnormalities relative to transmural myocardial perfusion in anesthetized dogs. Circulation 1980;62:1266-74.

22. Timmer SA, Teunissen PF, Danad I, Robbers LF, Raijmakers PG, Nijveldt $R$, et al. In vivo assessment of myocardial viability after acute myocardial infarction: A head-to-head comparison of the perfusable tissue index by PET and delayed contrast-enhanced CMR. J Nucl Cardiol 2016. doi:10.1007/s12350-015-0329-7.

23. deKemp RA, Klein R, Beanlands RSB. 82Rb PET imaging of myocardial blood flow-have we achieved the 4 " $R$ "'s to support routine use? EJNMMI Res 2016. doi:10.1186/s13550-016-0225-4.

24. Kim RJ, Fieno DS, Parrish TB, Harris K, Chen EL, Simonetti O, et al. Relationship of MRI delayed contrast enhancement to irreversible injury, infarct age, and contractile function. Circulation 1999;100:1992-2002.

25. Sciagra R, Bolognese L, Rovai D, Sestini S, Santoro GM, Cerisano G, et al. Detecting myocardial salvage after primary PTCA: early myocardial contrast echocardiography versus delayed sestamibi perfusion imaging. J Nucl Med 1999;40:363-70.

26. Ndrepepa G, Mehilli J, Martinoff S, Schwaiger M, Schomig A, Kastrati A. Evolution of left ventricular ejection fraction and its relationship to infarct size after acute myocardial infarction. J Am Coll Cardiol 2007;50:149-56.

27. Lekx KS, deKemp RA, Beanlands RS, Wisenberg G, Wells RG, Stodilka RZ, et al. Quantification of regional myocardial blood flow in a canine model of stunned and infarcted myocardium:
Comparison of rubidium-82 positron emission tomography with microspheres. Nucl Med Commun 2010;31:67-74.

28. Slart RH, Glauche J, Golestani R, Zeebregts CJ, Jansen JW, Dierckx RA, et al. PET and MRI for the evaluation of regional myocardial perfusion and wall thickening after myocardial infarction. Eur J Nucl Med Mol Imaging 2012;39:1065-9.

29. Juarez-Orozco LE, Glauche J, Alexanderson E, Zeebregts CJ, Boersma HH, Glaudemans AW, et al. Myocardial perfusion reserve in spared myocardium: correlation with infarct size and left ventricular ejection fraction. Eur J Nucl Med Mol Imaging 2013;40:1148-54.

30. Slart RH, Bax JJ, van Veldhuisen DJ, van der Wall EE, Dierckx RA, de Boer J, et al. Prediction of functional recovery after revascularization in patients with coronary artery disease and left ventricular dysfunction by gated FDG-PET. J Nucl Cardiol 2006;13:210-9.

31. Lautamaki R, Schuleri KH, Sasano T, Javadi MS, Youssef A, Merrill $\mathrm{J}$, et al. Integration of infarct size, tissue perfusion, and metabolism by hybrid cardiac positron emission tomography/computed tomography: Evaluation in a porcine model of myocardial infarction. Circulation Cardiovasc Imaging 2009;2:299-305.

32. Cuculi F, Dall'Armellina E, Manlhiot C, De Caterina AR, Colyer $\mathrm{S}$, Ferreira V, et al. Early change in invasive measures of microvascular function can predict myocardial recovery following PCI for ST-elevation myocardial infarction. Eur Heart J 2014;35:1971-80 